Michelle Dwerryhouse*, Belinda Winder, Nicholas Bladgen \& Rebecca Lievesley

Sexual Offences, Crime and Misconduct Research Unit, Psychology, Nottingham Trent University, 50 Shakespeare Street, Nottingham, NG1 4FQ

*All correspondence should be addressed to Michelle Dwerryhouse, Nottingham Trent University, 50 Shakespeare Street, Nottingham, NG1 4FQ, UK. (e-mail: michelle.dwerryhouse@ntu.ac.uk).

Declarations of Interest:

BW is the trustee of a UK charity delivering Circles of Support and Accountability; she is also leading the national UK evaluation of Big Lottery funded Community-based Circles of Support and Accountability. NB, RW and MD are co-investigators of the evaluation. 


\title{
Conceptualising Success and Failure in Circles of Support and Accountability
}

\begin{abstract}
This paper presents an exploration into success and failure in Circles of Support and Accountability (Circles). Successes in Circles are commonly reported in the literature whilst failure, for reasons relating to funding of the intervention, are often ignored. A disregard for the small number of Circles that fail, means an opportunity to learn from failure is lost. Furthermore, it is argued that, without agreed-upon definitions of success and failure within the context of Circles, it is not possible to ensure researchers and academics are measuring successes of the intervention to the same degree. This paper proposes a means for which to define success and failure in Circles. Success and failure were defined here, through a critical exploration of the literature, combined with a critical evaluation of the two core principles upon which the Circles intervention was based; no more victims and no one is disposable.
\end{abstract}

Keywords: Circles of Support and Accountability; CoSA; Restorative Justice; Outcome evaluation; Circles 


\section{Introduction}

Circles of Support and Accountability (Circles) is an intervention in which individuals in the community volunteer their time to offer practical and emotional support to someone with prior sexual offence convictions, whilst also holding them to account for their future behaviour (see Elliott et al, 2017 for a detailed review of the development, history, research and future directions of Circles). Circles exist to help people with sexual offence convictions reintegrate whilst also supporting their desistance efforts. Within Circles those in receipt of support are referred to as the 'Core Member'. The Core Member is supported in the community by four to six trained volunteers from the community. Volunteers come from various backgrounds and choose to support the Core Member in their own time (see Gilliam, Novak, Northcutt Bohmert \& Duwe, 2020; Höing, Bogaerts \& Vogelvang, 2017) for research with Circle volunteers). The Core Member and volunteers usually meet once a week for around an hour. Initial meetings often take place in private settings such as church halls or probation offices. After some time, meetings progress into the community and may include trips to coffee shops or social days out. Circles are usually planned to last for 12-18 months, with some ending earlier and others lasting longer, dependent upon the needs of the Core Member (Wilson, McWhinnie, Picheca, Prinzo $\&$ Cortoni, 2007). Recent research indicated that 95 successful Circles had a mean length of 14 months (Winder et al, 2020). The Core Member and volunteers are supported by a Circle coordinator. The coordinator is responsible for training volunteers and addressing any problems within the Circles. The coordinator is also responsible for providing progress reports to the wider circle of professionals within the criminal justice service, that are involved with the Core Members life (Wilson et al, 2007). Circles subscribe to the Risk-Need-Responsivity (RNR) model (Bonta \& Andrews, 2007) and the Good Lives Model (Ward \& Stewart, 2003). 
Circles adopt the RNR principles in the following way; potential Core Members are selected based on their perceived risk of recidivism. Only those assessed as high to medium risk are offered the opportunity to join a Circle whilst those deemed to be the highest risk are prioritised for inclusion (Wilson \& McWhinnie, 2016). Circles address the need principle through an individualised approach taken within each Circle. Circle volunteers are selected specifically for their fit with the Core Member, based on shared interests. Additionally, the Core Members personal aims and objectives are addressed at the beginning of the Circle, for the Circle to work towards. Whilst Circles is not a treatment intervention, the process of treating the Core Member as an individual with specific needs, addresses the responsivity principle. Circles have developed quickly and developments in volunteer training have enabled Circles to be designed specifically for minority groups, such as Core Members with intellectual disabilities; autistic spectrum conditions; young people; transgender and deaf individuals (Hocken et al., 2008). Whilst the RNR model has been subject to criticism relating to the models theoretical grounding, delivery in practice and blanket approach (Ward, Melser \& Yates, 2006), the three principals were used as a basis on which to build a theoretical model of Circles (Wilson, Pichea \& Prinzo, 2005). A key criticism of the RNR Model is the way in which recidivism is addressed through punitive measures that target risk rather than positivist measures which address individual needs (Ward et al., 2006). The Good Lives Model (GLM) developed by Ward and Stewart (2003) addresses some weaknesses of the RNR model. The GLM has been retrospectively applied to Circle practices, with elements of the GLM drawn upon in the development of Circle specific principles (Wilson, McWhinnie \& Wilson, 2008).

The GLM augments the risk-based model by placing equal emphasis on giving 'offenders the capabilities to secure important personal and social experiences ('goods') in acceptable ways' (Mann, 2004, pg.148). 
The GLM is a positivist, strength-based approach to offender rehabilitation. Within the GLM, offenders are argued to be driven by desires and needs in the same way that nonoffenders are. These desires and needs are referred to in the GLM as primary human goods and take many forms, from achievement in work and relationships to happiness, community, and autonomy (Ward, Mann \& Gannon, 2006). It has been argued that offenders differ from the non-offending public because they use maladaptive techniques to obtain their primary goods (Purvis, Ward \& Willis, 2011). Therefore, the GLM encourages offenders to first identify and then amend these maladaptive techniques for acquiring primary goods, to obtain primary goods in a pro-social way. Unlike the RNR model, the GLM encourages an offender to be viewed as an individual who is more than the offence they have committed (Ward \& Stewart, 2003). The GLM was designed to be used on all offender types although research has shown how it can be adapted to work specifically with individuals who commit sexual offences (Willis, Yates, Gannon \& Ward, 2012). The GLM has been utilised in the earliest development of UK based Circles, through the adoption of GLM principles (Wilson et al., 2008). Core Members are treated respectfully and encouraged to develop a new positive identity, whilst supported to pursue positive life goals through pro-social means (Bates, McCrae, Williams \& Webb, 2012). The first step toward this goal is evident in the way Circles refer to individuals with prior convictions of sexual offences as Core Members. This provides the Core Member with a positive identity to live up to, whilst simultaneously leaving behind the offender identity (Höing et al, 2013). This identity transformation offers the first basic step in which Core Members can work towards their future as they build their good life plan (Purvis et al., 2011). Figure 1 provides a graphic representation of the Circle model. 

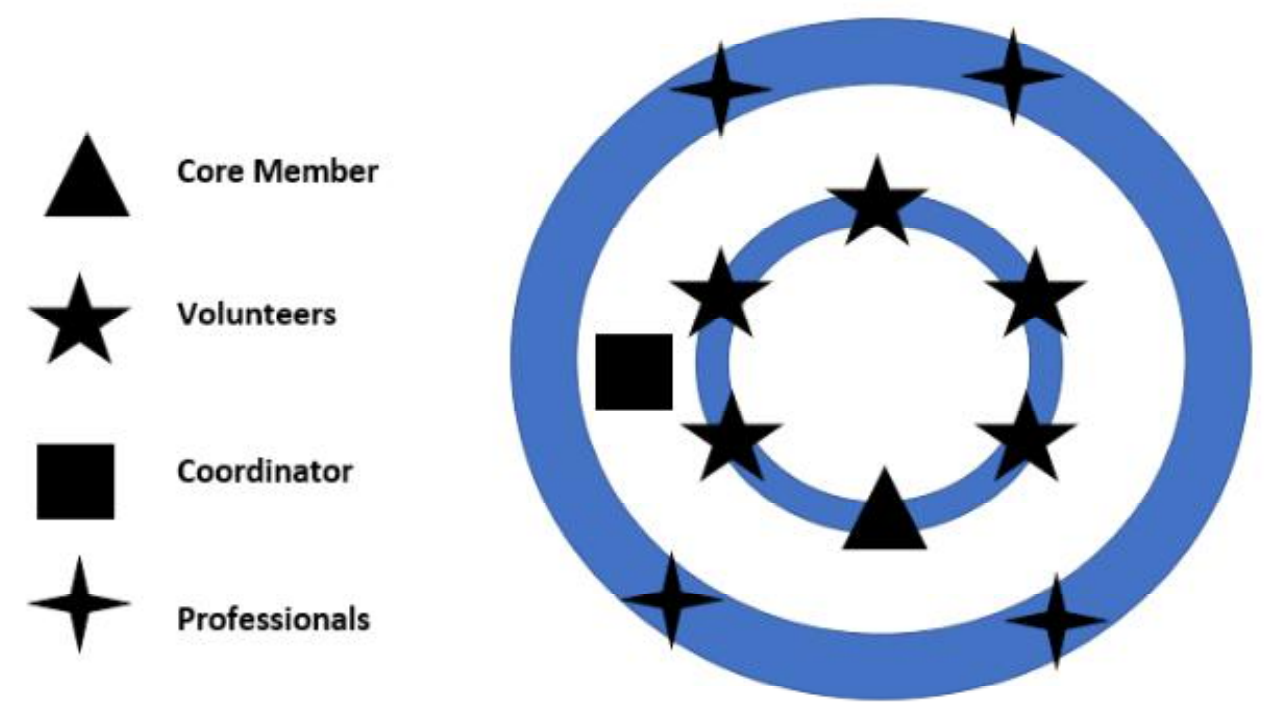

Figure 1 Graphic Representation of Circle Model

The inner Circle of volunteers support the Core Member in expressive and instrumental ways (Bohmert, Duwe \& Hipple, 2018). Expressive support is offered through encouragement of pro-social activities, open discussion of risk-related thoughts and someone to talk to about anything troubling the Core Member. Instrumental support may include such tasks as helping the Core Member seek employment, write a cv or identify community social groups. The coordinators role is to provide training to the volunteers and prepare the volunteers for the Circle. Coordinators also supervise the Circle, address any problems which may arise such as disagreements or volunteer dropouts and report on Circle progress to the outer Circle of professionals. The professionals in the outer Circle are individuals involved in the Core Members life before commencement of the Circle and are not usually involved in meetings, except for occasional review meetings. It is often the professionals in the Core Members life that make the original referral.

\section{Purpose of Review}

Much research into Circles has reported upon the successes of the intervention. Successes are usually reported in terms of desistance or a reduction in the severity of crime 
committed (Duwe, 2018). Successes have also been reported as improvements to Core Members personal circumstances such as housing and employment (Clarke, Brown \& Völlm, 2015) and improvements to Core Members emotional wellbeing (Höing, Bogaerts \& Vogelvang, 2013). Yet there is a paucity of research that explores the small number of instances whereby the intervention is less successful or fails in some way. Academics have called for further research into the resultant effects of the differing causes leading to failed Circles (Höing, Vogelvang \& Bogaerts, 2015) and Circle processes (Bates et al, 2013). Whilst Clarke, Brown and Völlm (2015) have argued that Circle effectiveness can only be evaluated through the inclusion of Circle non-completers and Duwe (2018) stated that future research should consider failed Circle start-ups to improve practices. Without clear guidelines upon which to measure success and failure within Circles, it is difficult to ensure measures of success and failure are being assessed to the same degree. Therefore, the purpose of this review paper is to propose a mechanism in which to measure success and failure within Circles. This will enable success to be measured and provide the opportunity to learn from failure. The present conceptualisation of success and failure was developed through a critical exploration of indicators of success and failure reported in the Circle literature (Duwe, 2018; Clarke, Warwick \& Völlm, 2017; Fox, 2016; Wilson \& McWhinnie, 2016; McCartan, 2016; Fox 2015; Clarke, Brown \& Völlm, 2015; Höing, Vogelvang \& Bogaerts, 2015; Höing, Bogaerts \& Vogelvang, 2015; Bates, Williams, Wilson \& Wilson, 2013) combined with a critical review of the two key principles upon which Circles was based (Hannem \& Petrunik, 2007). In the remainder of this paper, each of these topics are reviewed before the present proposal of how success and failure should be conceptualised and categorised is presented.

\section{Benefits of Circles}

Success in Circles is predominantly measured through a reduction in sexual recidivism, especially by funding bodies. Clarke et al. (2015) argued that due to the numerous 
methodological limitations of studies investigating the effectiveness of Circles, a reduction in sexual reconvictions by Core Members cannot be claimed as an outcome. However, researchers have identified other, 'softer benefits' of Circle participation. Clarke et al. (2015) identified that Circle participation reduced Core Member isolation through community integration, improvements in pro-social attitudes and activities such as volunteering and employment, improvements in age-appropriate relationships and improvements in emotional well-being such as increased self-esteem. Furthermore, Höing, Vogelvang, Bogaerts (2015) reported that participation in Circles improved Core Member self-reflection, openness and assertiveness and Core Members demonstrated improvements in self-esteem and self-confidence. Whilst improvements in 'soft benefits' are positive. Organisations that seek to secure funding are more interested in 'hard benefits' of reduced recidivism. Public attitudes towards individuals with sexual offence convictions are inherently negative. Because funders decisions are influenced by public opinion, a reduction in Core Member recidivism has become the key focus. Duwe (2018) conducted a randomised control trial (RCT) in Minnesota and demonstrated that Circles do reduce Core Member Recidivism. To date, there have been no RCTs in the UK so the effectiveness of Circles upon Core Member desistance in the UK, cannot yet be ascertained.

Although there is a paucity of research into failure in Circles, studies have noted some factors which lead to early unplanned Circle endings. The term failure is actively avoided in the literature and therefore it is unclear whether instances of 'unsuccessful' or 'unplanned endings' are deemed as failures. Unplanned endings can be broadly defined as: Core Member exclusion, recall to prison and Core Member dropout (Bates, Williams, Wilson \& Wilson, 2013; Höing, Vogelvang \& Bogaerts, 2015). Core Members have been excluded from Circles due to a lack of cooperation (Höing, Vogelvang \& Bogaerts, 2015). There have been occasions where Core Members have been recalled to prison for historical offences (Bates et al., 2013). In other cases, Core Members have cited reasons for their voluntary withdrawal as 
a lack of motivation (Bates et al., 2013), concerns over a lack of volunteer commitment or cooperation (Höing, Vogelvang \& Bogaerts, 2015) and a strong focus on accountability (Fox, 2015). Höing, Vogelvang and Bogaerts (2013) capture these issues in their Intervention model.

\section{Guiding Principles of Circles}

Circles were originally established in Canada using two core principles, no more victims and no one is disposable (Hannem \& Petrunik, 2007). It is these core principles which steer the aims of Circles and therefore influence perceptions of success and failure. Taking the first core principle, no more victims, one goal of Circles is to promote desistance so that the Core Member receiving support does not go on to reoffend again in the future (Höing et al, 2013; Hannem \& Petrunik, 2007). The second core principle, no one is disposable, refers to the Core Members in receipt of support; a goal of Circles being to support the Core Members reintegration with society (Elliott \& Beech, 2012). The Core Member is viewed as an individual with the potential to positively contribute to society, as a person that should not be left behind or excluded. Therefore, success, as defined by the two core principles, means a Core Member will not go on to reoffend and is positively reintegrated with society (Höing et al, 2013; Elliott \& Beech, 2012; Hannem \& Petrunik, 2007). Arguably, if either of these two core principles are not met, the Circle may be deemed to have failed. There are several ways in which success and failure could be defined in Circles and several outcomes which would be deemed as less than successful. Failure in Circles is not straightforward but it is an area which requires attention. Without the presence of a universally employed definition of success and failure, we cannot be sure that facilitators and researchers are evaluating outcomes to the same degree, which would bring into question the validity of such evaluations. 


\section{Defining Success in Circles}

The aim of Circles is to prevent reoffence (Höing, Vogelvang, Bogaerts, 2015). Whilst of clear importance for the safety of the public, desistance is further beneficial to the Core Member. However, in some cases, Core Members may not see the immediate benefit of desisting whilst they focus instead upon their additional needs with which they require support. It can be easy to view the guiding principles of no more victims and no one is disposable (Hannem \& Petrunik, 2007) in terms of the needs of the public and criminal justice service versus the needs of the Core Member. This is not a helpful view. Whilst funding for Circle initiatives are sought on the basis that Circles reduce recidivism directly, it is likely that through supporting Core Members practical needs and emotional wellbeing, Core Member desistance will develop organically (Höing et al., 2013). Therefore, it may be beneficial to measure success on several levels. Improvements to Core Member wellbeing maintain the core principle of no one is disposable. However, if a Core Member chooses to reoffend despite receiving support, the Circle must be deemed a failure due to violation of the core principle of no more victims. Much of the Circles literature has reported upon areas of achievement within Circles such as those relating to improved wellbeing and social skills (see table 1 below). Many Circles with such achievements go on to have successful outcomes. However, Core Members that make gains in their wellbeing and social skills but go on to reoffend are distinctively different to those that make positive gains and choose to lead an offence free life. It is important to differentiate between the two, in order to learn from those that are less successful. Table 1 details some indicators of success and failure as captured in the literature. 


\begin{tabular}{|c|c|c|}
\hline Research and Evaluation & Indicators of Success & Indicators of Failure \\
\hline $\begin{array}{l}\text { Bates, Williams, Wilson and } \\
\text { Wilson (2013) }\end{array}$ & & $\begin{array}{l}\text { Recidivism outcomes: } \\
\text { Violent, non-violent, } \\
\text { failure to comply with } \\
\text { sex offender registry, } \\
\text { non-contact sexual } \\
\text { offence, contact sexual } \\
\text { offence, breach of SOPO. }\end{array}$ \\
\hline $\begin{array}{l}\text { Clarke, Brown and Völlm } \\
\text { (2015) }\end{array}$ & $\begin{array}{l}\text { Psychosocial adaptation, } \\
\text { housing, relationships, and } \\
\text { employment. }\end{array}$ & $\begin{array}{l}\text { Recidivism outcomes: } \\
\text { reconviction for any } \\
\text { offense and any sexual } \\
\text { offense, reoffending, } \\
\text { arrest, recall, and breach } \\
\text { of license. }\end{array}$ \\
\hline $\begin{array}{l}\text { Clarke, Warwick and Völlm } \\
\text { (2017) }\end{array}$ & & $\begin{array}{l}\text { Non-engagement, } \\
\text { Withdrawal, Recall. }\end{array}$ \\
\hline Duwe (2018) & & $\begin{array}{l}\text { Recidivism measures: re- } \\
\text { arrest, reconviction, } \\
\text { resentenced to prison for } \\
\text { a new felony conviction } \\
\text { or reimprisonment for a } \\
\text { technical violation } \\
\text { revocation. }\end{array}$ \\
\hline Fox (2015) & $\begin{array}{l}\text { Reduced recidivism, } \\
\text { Desistance. }\end{array}$ & \\
\hline Fox (2016) & $\begin{array}{l}\text { Reduced recidivism, } \\
\text { Desistance. }\end{array}$ & \\
\hline $\begin{array}{l}\text { Höing, Bogaerts and } \\
\text { Vogelvang (2013) }\end{array}$ & $\begin{array}{l}\text { Prevention of sexual and } \\
\text { general recidivism. } \\
\text { Development of a positive } \\
\text { identity and pro-social } \\
\text { lifestyle. }\end{array}$ & \\
\hline $\begin{array}{l}\text { Höing, Vogelvang and } \\
\text { Bogaerts (2015) }\end{array}$ & $\begin{array}{l}\text { Full desistance, development } \\
\text { of a pro-social lifestyle. }\end{array}$ & $\begin{array}{l}\text { Core Member dropout } \\
\text { and lack of cooperation } \\
\text { with Circles. }\end{array}$ \\
\hline McCartan (2016) & & Recidivism \\
\hline $\begin{array}{l}\text { Wilson and McWhinnie } \\
\text { (2016) }\end{array}$ & $\begin{array}{l}\text { Reduced recidivism, } \\
\text { Desistance. }\end{array}$ & \\
\hline
\end{tabular}


Whilst it has been argued that differences amongst outcomes should be further explored and considered as distinct entities. Achievements throughout the duration of the Circle should equally be monitored and appraised. Core Members are individuals with their own individual life goals. Some Core Members may wish to reintegrate with society in positive ways such as, through gaining employment, finding new hobbies, making new friends or reconnecting with old friends and family. As social isolation is among one of the most widely accepted risk factors for recidivism (Malinen, Willis \& Johnston, 2014), it is very likely that through the process of reintegration and reduced isolation, that desistance may take place as a by-product (Höing et al., 2013). Additionally, through concentrating efforts on reintegration processes, Core Members are further supported in stepping away from their offender identity (Fox, 2016). In terms of measuring success in Circles, achievements in obtained accommodation; employment; volunteering; inclusion in social activities; development of new social connections outside of the Circle; increases in self-esteem; confidence and other measures of wellbeing should be viewed and celebrated as successes on the Core Members journey toward tertiary desistance. The Circle intervention model developed by Höing et al. (2013) illustrates such factors as intermediate effects that should be acknowledged as successes in the Circles as they are achieved. Arguably, positive progress could be identified by individuals supporting any Core Member in any Circle. Some Core Members may demonstrate minimal progress whilst others demonstrate significant improvements. To date, success in Circles has been measured in numerous ways. However, Circles was developed on the basis of two core principles and whilst all achievements made within the Circle should be acknowledged and celebrated, if Circles are to be measured critically, it is the final outcomes which should ultimately define whether a Circle is deemed to have succeeded or failed. 


\section{Defining Failure in Circles}

Table 1 listed some descriptors of failure as recorded in the literature which broadly cover Core Member recidivism and poor engagement inclusive of Core Member withdrawal. Voluntary withdrawal from Circles at the decision of the Core Member should be disregarded as failure, as this does not violate either of the two core principles. Additionally, Core Member attendance is voluntary. Therefore, Core Members should have the right to withdraw, without the Circle being deemed an automatic failure. As Clarke, Warwick and Völlm (2017) stated, unplanned endings do not always imply failure. The present discussion argues that failures are more accurately measured by the outcomes of volunteer disbandment, Core Member Exclusion and Core Member re-offence.

Volunteer disbandment and Core Member Exclusion are common amongst unplanned endings, yet each are potentially avoidable. Volunteer disbandment refers to cases whereby the volunteers drop-out of the Circle, either due to personal commitments outside of the Circle or a lack of motivation to continue. Core Member exclusion refers to cases whereby the Core Member is forced out of the Circle for reasons relating to the Core Members lack of cooperation or motivation to engage, despite the volunteers being otherwise available to offer support. Whilst the categories appear similar, they can be differentiated in the reasoning behind the volunteer's disengagement. The prior reasoning relates to volunteers' personal circumstances and willingness to engage, whilst the latter relates to volunteer and/or Coordinator perceptions of Core Member willingness to engage. Each of these shall be considered in turn.

\section{Volunteer Disbandment}

Höing et al. (2013) explored the experiences of individuals involved in Circles through qualitative research with Circle members inclusive of volunteers, Core Members, and coordinators. In 6 of the 21 Circles investigated, it was reported that a dysfunctional stage took place. Dysfunctional stages were characterised by low levels of trust and openness, and 
exclusionary behaviour of volunteers toward the Core Member amongst other behaviours (Höing et al., 2013). Such exclusive behaviours are inverse to the desired characteristics of volunteers advocated in the Intervention Model (Höing, Vogelvang \& Bogaerts, 2015) and breed a poor therapeutic environment. The authors argued that the selection of suitable volunteers is crucial to the success of Circles. Volunteers with questionable motivations, noninclusive behaviour toward the Core Member or limited commitment to Circles can lead to ruptures in the Circle. Such ruptures can lead to the Circle ending prematurely through disbandment of the volunteers or Core Member drop-out (Höing et al., 2013). It would be beneficial to evaluate group cohesion in Circles to see if dysfunctional stages can be avoided.

Kerr, Tully and Völlm (2017) investigated the attitudes of Circle volunteers towards Core Members and reported that volunteers viewed Core Members social isolation to a similar level to the public. Additionally, volunteers viewed Core Members to be slightly more dangerous than the public did, although not to a significant level. Kerr et al. (2017) suggested that such volunteer attitudes may be adaptive in the functions of providing support and accountability. However, volunteer concerns over Core Member dangerousness may impact volunteer commitment to Circles. Particularly so, if volunteers feel unsafe spending time with the Core Member.

Research has shown that volunteering within Circles can be a stressful task due to the intensive nature of work involved (Höing, Bogaerts \& Vogelvang, 2016). Because a lack of volunteer commitment has been cited as a reason for Core Member voluntary dropout, this holds implications for the selection and recruitment of suitable volunteers. Watson, Thomas and Daffern (2015) noted how the therapeutic environment can negatively affect outcomes for individuals with prior convictions. Research by Höing, Vogelvang and Bogaerts (2015) noted a case where a Core Member voluntarily withdrew, due to the negative attitudes of his volunteers toward him. Volunteer non-attendance may also have a negative impact upon Core 
Members, whether limited attendance be a result of low motivation for the Circle or limited availability due to personal circumstance (Kitson-Boyce, Blagden, Winder \& Dillon, 2019). Cases such as this highlight the importance of selective volunteer recruitment and subsequent training. Beyko and Wong (2005) argued that good therapeutic relationships can reduce dropout from treatment. Whilst Circles are not a treatment, it is argued that similarly, such negative effects may be reversed through positive relationships.

\section{Core Member Exclusion}

Core Members have been excluded from Circles due to poor cooperation (Höing, Vogelvang \& Bogaerts, 2015). McCartan (2016) reported how Core Members believed Circles existed to support Core Members rather than hold them accountable. It appears that some Core Members choose to participate in Circles with certain ideas about the process, possibly considering Circles to be a support network, then later lack motivation to engage upon the realisation that the accountability aspect is equally asserted within the Circle. Circles that focus their discussions on support rather than accountability, may be more successful due to the encouragement of new identity formation within the Core Member (Fox, 2016). Whilst Circles that remain focused on accountability, may inhibit the Core Member from exploring positive new identities away from the offender stereotype (Fox, 2016).

Circles are designed to be inclusive; all members are viewed as equals within the Circle and agree to behave in such a way upon commencement. If the volunteer members of the Circle choose to focus upon the Core Members accountability, without concern for the Core Members wellbeing as an equal, the Core Member is likely to feel excluded and may perceive the intervention as a Circle of Accountability (CoA) rather than one which additionally incorporates support. In theory, such volunteer behaviours could lead to Core Member isolation and exclusion from the group, whilst devolving the Core Members social identity into that of an offender. McCartan (2016) asserted that it is important that all parties involved in Circles 
understand what is meant by the terms support and accountability. A clear understanding at the outset would allow potential Core Members to make an informed decision as to whether to participate. Allowing for willing individuals to participate with full knowledge of what they are agreeing to. If Core Members choose to join a Circle with full knowledge of what is expected of them it seems likely that they would be more cooperative and therefore provide volunteers with less reason to exclude them from Circles. Furthermore, Ware and Blagden (2016) argue that within a treatment setting, an offender's disruptive behaviour should not be used as an excuse to exclude individuals from therapy.

Using the guiding principles, Table 2 illustrates a simple decision matrix from which the Circle outcome can be defined in terms of success and failure. Table 2 provides an exhaustive list of all potential Circle outcomes. There may be certain circumstances whereby the Circle ends for a specific reason not listed in the matrix, for example Core Member illness. In such cases, the matrix can still be used to categorise the ending based upon whether the ending was agreed by all or the Core Member chose to dropout. In either of these examples the ending would be deemed as a success.

\begin{tabular}{|c|c|c|c|}
\hline $\begin{array}{c}\text { Circle Ending } \\
\text { Circle) }\end{array}$ & $\begin{array}{c}\text { No More } \\
\text { Victims } \\
\text { New Offence (that was not identified by the }\end{array}$ & $\begin{array}{c}\text { No-one is } \\
\text { Disposable }\end{array}$ & Outcome \\
\hline $\begin{array}{c}\text { Recall due to Circle Intelligence preventing a } \\
\text { new offence }\end{array}$ & & & Failure \\
\hline Planned and agreed ending & & & Success \\
\hline Core Member decision to end (dropout) & & $\mathrm{X}$ & Failure \\
\hline Volunteer Disbandment & & $\mathrm{X}$ & Failure \\
\hline Core Member Exclusion & & & \\
\hline
\end{tabular}

Table 2 Decision Matrix of Circle Endings and Outcome Definitions 
Under this matrix, all Circles with a new reoffence within the term of the Circle are deemed failures with one exception. If a Core Member has been recalled based on Circle intelligence that prevents the Core Member carrying out a new offence, the Circle should be deemed a success due to the accountability aspect of Circles. New offences defy the core principle of no more victims. Where a new offence or recall does not take place, success and failure are still upheld by the two core principles. Circles with planned and agreed endings are deemed a success as the two core principles are maintained. In instances whereby the Core Member voluntarily chooses to withdraw from the Circle, the ending should be deemed a success due to the two core principles being upheld. However, if the Circle ends due to volunteer disbandment the core principle of No one is disposable is violated and the Circle should be deemed a failure as the Core Member is left without support. It is important to clarify that volunteer disbandment described here, does not refer to instances whereby one or two volunteers leave the Circle and are easily replaced. Volunteer disbandment refers to instances whereby all volunteers choose to leave the Circle, either at the same time or within close proximity. In this scenario a new Circle of volunteers may be offered to the Core Member, yet the initial Circle will have failed through violation of the core principle No one is disposable. Finally, if the decision to end the Circle is taken by external agencies and the Core Member is excluded from the Circle, without evidence of recall or reoffence, the ending should also be deemed a failure due to violation of the core principle No one is disposable.

\section{Potential Implications of Circle Attrition and Dropout}

One way of beginning to explore attrition and dropout in Circles is to consider the reasons for treatment attrition and dropout amongst individuals convicted of sexual offences. Larochelle, Diguer, Laverdière and Greenman (2011) evaluated the literature on treatment attrition and developed three main causes of treatment non-completion. Larochelle et al. (2011) 
reported causes of treatment attrition as premature termination by the offender; exclusion from treatment by the treatment team on the grounds of unacceptable behaviour or lack of participation; and termination of treatment due to recall to prison or a failure to comply with probation release conditions. Each cause can be likened to the three identified reasons for Circle attrition: dropout, exclusion and recall (Bates et al., 2013; Höing, Vogelvang \& Bogaerts, 2015). Research has evidenced that individuals who drop out of treatment have higher rates of recidivism than treatment completers (Hanson et al., 2002). Furthermore, individuals who have had their treatment terminated early by a therapist have been evidenced to re-offend at a higher rate than those who drop-out from treatment (Romine, Miner, Poplin, Dwyer \& Berg, 2012). Due to the similarities in attrition between treatment interventions and Circles, there may be cause for concern over Core Members who choose to voluntarily withdraw from Circles earlier than planned. In addition to cases whereby Core Members are left without a Circle due to volunteer disbandment or exclusion. In the absence of a theoretical construct of Circle failure, it is argued that unsuccessful treatment interventions are used as a basis from which to understand the potential implications of unsuccessful Circles. The decision matrix proposed earlier, defines success and failure during the term of the Circle. Due to long-term potential implications of unsuccessful Circles, it is important to also evaluate the effectiveness of Circles upon long-term Core Member desistance.

\section{Conceptualising Success and Failure Beyond the term of the Circles}

Identifying individual Circle outcomes to categorise success and failure is useful in acknowledging the level of success achieved by the Circle intervention. Furthermore, the use of an agreed upon definition of what constitutes a success or failure within Circles, would minimise over-reporting of ambiguous Circle completions as successes, such was the case in (Bates et al, 2012). 
Whilst Core Member dropout and exclusion from the Circles may occur during the term of the Circle, recall to prison or re-arrest may occur during the Circle or following completion of the Circle. This complicates matters. If a Circle lasts 12 months and completes as planned but the Core Member reoffends three months following the closure of the Circle, it would be a very limiting conceptualisation to consider the Circle a success. It is acknowledged in the literature that the longer an individual is out in society without reoffending, the lower their future risk of reoffence becomes (Hanson, Harris, Helmus \& Thornton, 2014). However, some Circles have been deemed successfully completed, even when the Core member has subsequently gone on to reoffend (Bates et al., 2012). If the aim of evaluating Circles is to evaluate the ability of Circles to reduce Core Member risk during the term of the Circle this may be acceptable. However, as a core principle of Circles is no more victims it seems unacceptable that the Circles be deemed a success, if the Core Member goes on to reoffend following completion of the Circle term. Through participation in Circles, Core Members are provided with a support network which they can use to build upon their self-esteem, confidence and life skills. Arguably, as the support network is gradually removed, it is up to the Core Member to harness their new-found life skills to move forward positively with an offence free life. Thus, it is appropriate to distinguish between the effectiveness of Circles during a Core Members participation and the lasting effectiveness of Circles post-completion. Success and failure are not clear-cut concepts in Circles and may benefit from being considered in terms of a timeline.

Figure 2 illustrates how success and failure may be considered as a timeline. The timeline illustrates the various ways in which Circle may end, along with when these endings may occur. Essentially the outcomes laid out in table 1 have been mapped onto the timeline presented in Figure 2. In terms of successful Circles, endings may be the result of planned completions of Core Member voluntary withdrawal, both of which occur during the term of 
the Circle. Alternatively, Circles that end due to recall as the result of Circle intelligence may occur during the Circle or theoretically, they could occur once the Circle has ended if contact is maintained between members of the Circle and the Core Member. In terms of failed Circles, Core Member Exclusion and volunteer disbandment can occur at any time during the term of the Circle, whilst re-arrest can occur either during the Circle or at any point post-Circle.

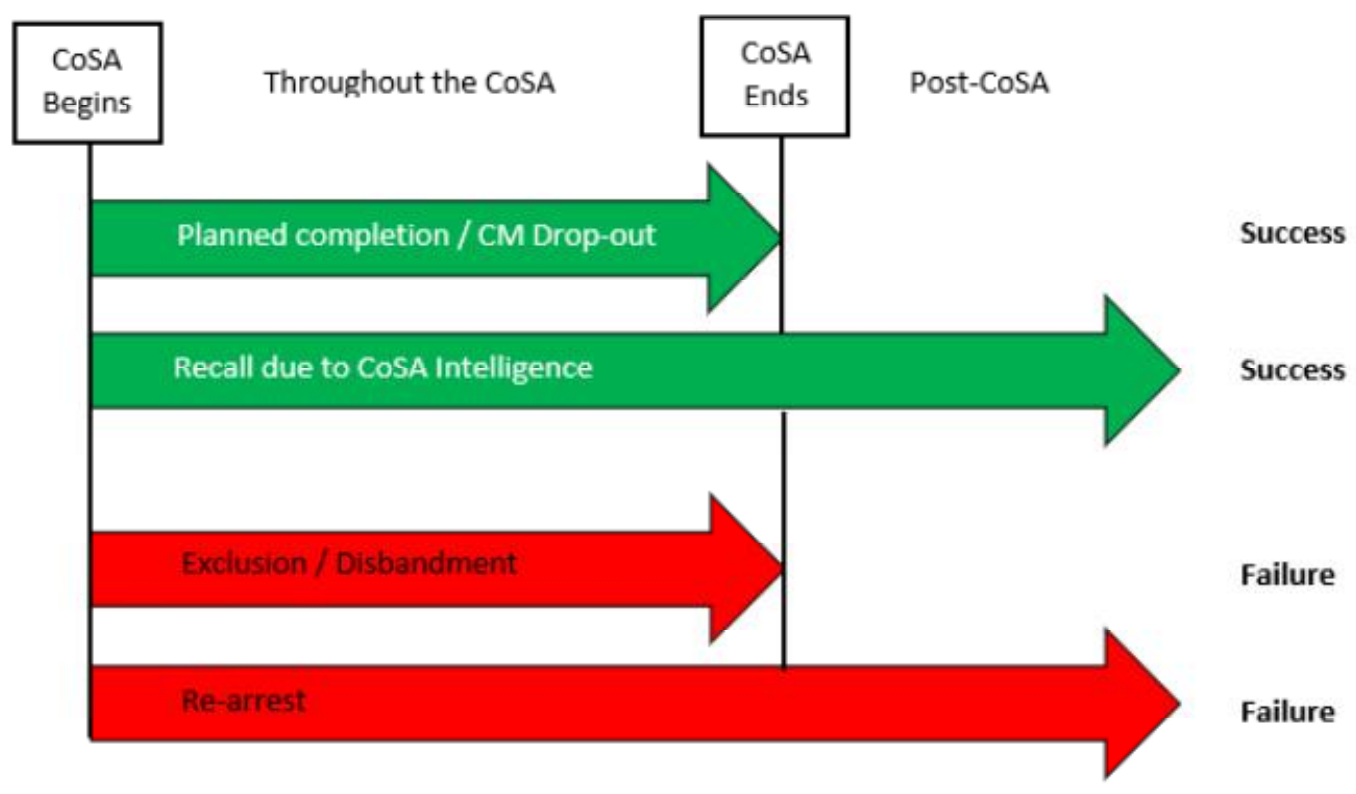

\section{Figure 2 Circle Timeline}

If a Circle is only effective during the term of the Circle, it is not particularly helpful in the long term. Core Members are made aware at the beginning that volunteer support will not be available indefinitely and Core Members must come to terms with this. In order for a Core Member to have the best opportunity for ongoing success post-Circle, it is important that the Circle spends time helping the Core Member to build a wider social network outside of Circle. At the time of writing, it is not known how long the positive effects of Circles last, nor if, or how, they 'wear off'. Circles is but one aspect of support, provided in addition to that of professionals in the Criminal Justice System, treatment interventions, and programmes completed whilst in prison. 
If a reoffence took place during the term of the Circle, the Circle would automatically be deemed a failure in the decision matrix, except for recall due to Circle intelligence. If the Circle were otherwise be deemed successful during the term of the Circle, the long-term success of the intervention can be evaluated post-Circle. At this point the core principle of no one is disposable is no longer relevant as the Core Member has already received the support of their Circle. However, the second core principle of no more victims still stands. Research has suggested that the benefits gained from Circle participation may promote Core Member desistance (Höing et al., 2013). However, it is presently unknown whether differences in Circle endings may influence Core Members recidivism risk. This is an area that requires further research. Hanson et al. (2014) carried out longitudinal research and asserted that in $(n=1992)$ high-risk cases, the sexual recidivism risk decreased from $22 \%$ upon release, to $8.6 \%$ after five years, and further decreased to $4.2 \%$ ten years post release. Additionally, only $7 \%$ of individuals reoffended within the first year following release. Individuals participating in Circles are supported to reduce their risk through support and reintegration. Therefore, the norms evidenced in the research of Hanson et al. (2014) may differ from that of those involved in Circles. The only longitudinal study on Core Member recidivism to date, indicates that Circles reduces the risk of sexual recidivism by $88 \%$ (Duwe, 2018). The results suggest that Circles are beneficial to Core Members in supporting their desistance and reintegration. Whilst evidence for Core Member desistance relies upon limited longitudinal research, Core Member behaviour following the closure of the Circle is the sole responsibility of the Core Member. Therefore, any reoffence should reflect upon the Core Member as an individual, and not of the wider Circle that offered support.

\section{Conclusion}

Research into Circles has predominantly focussed upon the successes of the intervention without much consideration given toward instances that have been less successful. 
Moreover, whilst there is general consensus that success can be measured through Core Member desistance, there have also been calls to evaluate successes in terms of Core Member achievements. Whilst it is important to acknowledge and celebrate Core Members achievements, instances of failure should be equally recognised and acknowledged. There is nothing to be gained from dismissing Circles that do not meet expectations and there is much potential to learn from Circles that fail. Furthermore, it has been recommended that a consistent approach is used when defining success and failure in Circles. A standardised assessment of success and failure is useful in three ways. Firstly, it provides a set of criteria against which to measure success and failure. Secondly, it allows for consistency in research and evaluation of Circles. Thirdly, it offers the opportunity to categorise success and failure as distinct binary categories. The clear separation of which provides the opportunity for further research into Circle failure. This review does not propose all-encompassing definitions of what constitutes success and failure in Circles. Rather, it is provided as a starting point to encourage discussion and thought around what exactly should define success and failure in the context of Circles. 


\section{References}

Bates, A., Macrae, R., Williams, D., \& Webb, C. (2012). Ever-increasing circles: A descriptive study of Hampshire and Thames Valley Circles of Support and Accountability 200209, Journal of Sexual Aggression, 18(3) 355-373. doi:10.1080/13552600.2010.544415.

Bates, A., Williams, D., Wilson, C., \& Wilson, R. J. (2013). Circles South East: The first 10 years 2002-2012. International Journal of Offender Therapy and Comparative Criminology, 58(7), 861-885. doi:10.1177/0306624X13485362

Beyko, M. J \& Wong, S. C. (2005). Predictors of treatment attrition as indicators for program improvement not offender shortcomings: A study of sex offender treatment attrition. Sexual Abuse: A Journal of Research and Treatment, 17(4), 375-389.

Bohmert, M. N., Duwe, G., \& Hipple, N. K. (2018). Evaluating restorative justice circles of support and accountability: can social support overcome structural barriers?. International journal of offender therapy and comparative criminology, 62(3), 739-758.

Clarke, M., Brown, S., \& Vollm, B. (2015). Circles of Support and Accountability for Sex Offenders: A Systematic Review of Outcomes. Sexual Abuse: A Journal of Research and Treatment, 1-33.

Duwe, G. (2018). Can circles of support and accountability (CoSA) significantly reduce sexual recidivism? Results from a randomized controlled trial in Minnesota. Journal of Experimental Criminology, 1-22.

Elliott, I, A. (2014, June 6). CoSA: An Inconvenient Truth [Web blog post]. Retrieved from https://nextgenforensic.wordpress.com/2014/06/06/cosa-an-inconvenient-truth/ 
Elliott, I. A., \& Beech, A. R. (2013). A UK cost-benefit analysis of circles of support and accountability interventions. Sexual Abuse, 25(3), 211-229.

Elliott, H., Hocken, K., Lievesley, R., Blagden, N., Winder, B., \& Banyard, P. (Eds.). (2018). Sexual crime and circles of support and accountability. Springer.

Fox, K. J. (2015). Contextualizing the policy and pragmatics of reintegrating sex offenders. Sexual abuse: a journal of research and treatment, 1079063215574711.

Fox, K. J. (2016). Civic commitment: Promoting desistance through community integration. Punishment \& Society, 18 (1), 68-94. doi: 10.1177/1462474515623102

Gilliam, M., Novak, M., Northcutt Bohmert, M., \& Duwe, G. (2020). Desires and Desirability of Volunteers in CoSA Programs. Sexual Abuse, 1079063220912454.

Hannem, S., \& Petrunik, M. (2007). Circles of Support and Accountability: A Community Justice Initiative for the Reintegration of High Risk Sex Offenders, Contemporary Justice Review, 10:2, 153-171, doi: 10.1080/10282580701372046

Hanson, R. K., Gordon, A., Harris, A. J., Marques, J. K., Murphy, W., Quinsey, V. L \& Seto, M. C. (2002). First report of the collaborative outcome data project on the effectiveness of psychological treatment for sex offenders. Sexual Abuse: A journal of research and treatment, 14(2), 169-194.

Hanson, R. K., Harris, A. J. R., Helmus, L., \& Thornton, D (2014). High Risk Sex Offenders May Not Be High Risk Forever. Journal of Interpersonal Violence, 29(15), 2792-2813. doi:10.1177/0886260514526062

Hocken, K., Good, C., Elliott, H., Webb, C., O’Connor, H., \& Cox, K. (2018). Future Directions: Alternative Circles of Support and Accountability Models for Minority Groups. In Elliott, H., Hocken, K., Lievesley, R., Blagden, N., Winder, B \& Banyard, 
P (Eds.), Sexual Crime and Circles of Support and Accountability (pp. 171-200).

Springer.

Höing, M., Bogaerts., S \& Vogelvang, B (2013). Circles of Support and Accountability: How and why they work for Sex Offenders. Journal of Forensic Psychology Practice, 13(4), $267-295$

Höing, M., Bogaerts, S., \& Vogelvang, B. (2016). Helping sex offenders to desist offending: The gains and drains for CoSA volunteers-A review of the literature. Sexual Abuse, 28(5), 364-402.

Höing, M., Bogaerts, S., \& Vogelvang, B. (2017). Volunteers in circles of support and accountability job demands, job resources, and outcome. Sexual Abuse, 29(6), 541-562.

Höing, M., Bogaerts., S \& Vogelvang, B (2015). Volunteers in Circles of Support and Accountability Job Demands, Job Resources, and Outcome. Sexual abuse: a journal of research and treatment, 1-22, doi:10.1177/1079063215612441

Höing, M., Vogelvang, B \& Bogaerts, S. (2015). “I Am a Different Man Now”-Sex Offenders in Circles of Support and Accountability A Prospective Study, International journal of offender therapy and comparative criminology, 0306624X15612431.

Kerr, N., Tully, R. J., \& Völlm, B. (2017). Volunteering With Sex Offenders: The Attitudes of Volunteers Toward Sex Offenders, Their Treatment, and Rehabilitation. Sexual Abuse, 1079063217691964.

Kitson-Boyce, R., Blagden, N., Winder, B., \& Dillon, G. (2019). Supporting Desistance Through Ambiguous Practice: What Can Be Learned From the First Prison-Based Model of CoSA in England and Wales?. Journal of Forensic Psychology Research and Practice, 19(2), 186-209. 
Larochelle, S., Diguer, L., Laverdière, O., \& Greenman, P. S. (2011). Predictors of psychological treatment noncompletion among sexual offenders, Clinical Psychology Review, 31(4), 554-562.

Malinen, S., Willis, G. M., \& Johnston, L. (2014). Might Informative media reporting of sexual offending influence community members' attitudes towards sex offenders?. Psychology, Crime and Law, 20(6), 535-552, doi:10.1080/1068316X.2013.793770

Mann, R. E. (2004). Innovations in sex offender treatment. Journal of Sexual Aggression, 10(2), 141-152.

McCartan, K. (2016). Circles of support and accountability: Cabinet office - Social Action Fund evaluation. Project Report. University of the West of England, Bristol, UK. Available from: http://eprints.uwe.ac.uk/28279

Purvis, M., Ward, T., \& Willis, G. (2011). The Good Lives Model in Practice: Offence Pathways and Case Management. European Journal of Probation, 3(2), 4-28.

Ward, T., Mann, R. E \& Gannon, T. A. (2006). The good lives model of offender rehabilitation: Clinical implications. Aggression and Violent Behavior, 12(1), 87-107.

Ward, T., Melser, J., \& Yates, P. M. (2007). Reconstructing the Risk-Need-Responsivity model: A theoretical elaboration and evaluation. Aggression and violent behavior, 12(2), 208-228.

Ward, T., \& Stewart, C. A. (2003). The treatment of sex offenders: Risk management and good lives. Professional Psychology: Research and Practice, 34(4), 353.

Ware, J., \& Blagden, N. (2016). Responding to Categorical Denial, Refusal, and Treatment Drop-Out. The Wiley Handbook on the Theories, Assessment and Treatment of Sexual Offending, 1559-1574. 
Watson, R., Thomas, S., \& Daffern, M. (2015). The impact of interpersonal style on ruptures and repairs in the therapeutic alliance between offenders and therapists in sex offender treatment. Sexual abuse: a journal of research and treatment. 1-20. doi:1079063215617514.

Willis, G. M., Yates, P. M., Gannon, T. A., \& Ward, T. (2012). How to Integrate the Good Lives Model Into Treatment Programs for Sexual Offending: An Introduction and Overview. Sexual Abuse: A Journal of Research and Treatment, 25 (2) 123-142, doi:10.1177/1079063212452618

Wilson, R. J., \& McWhinnie, A. J. (2016). Circles of Support \& Accountability: The Role of the Community in Effective Sexual Offender Risk Management, In Sexual Offending (pp. 745-754) Springer New York.

Wilson, R. J., McWhinnie, A., Picheca, J. E., Prinzo, M., \& Cortoni, F. (2007). Circles of support and accountability: Engaging community volunteers in the management of highrisk sexual offenders. The Howard Journal of Criminal Justice, 46(1), 1-15. https://doi. org/10.1111/j.1468-2311.2007.00450.x

Wilson, R. J., McWhinnie, A, J., \& Wilson, C. (2008). Circles of Support and Accountability: An international partnership in reducing sexual offender recidivism. Prison Service Journal, 138, 26-36

Wilson, R. J., Picheca, J. E., \& Prinzo, M. (2005). Circles of support and accountability: An evaluation of the pilot project in South-Central Ontario. Ottawa, Canada: Correctional Service of Canada.

Winder, B., Blagden, N., Lievesley, R., Dwerryhouse, M., Kitson-Boyce, R and Elliott, H (2020). UK National Evaluation of Big Lottery Funded Circles of Support and Accountability, Evaluation Report March 2020. Nottingham Trent University, UK. 